\title{
Researches regarding primary control in hydraulic systems
}

\author{
Irina Tița*, and Irina Mardare \\ Technical University "Gheorghe Asachi” of Iași, Department of Fluid Mechanics, Fluid Machinery \\ and Fluid Power Systems, Bvd. D. Mangeron, 59A, 700050, Iasi, Romania
}

\begin{abstract}
The technology in wind turbines has developed very rapidly but there are still a lot that can be improved also regarding new technologies. One example is wind turbine with hydraulic transmission. At the beginning low power wind turbines are in view. First of all the wind energy is meant to be used by isolated users for household and garden equipment or pumping water. Later, if results will be as expected, and wind potential satisfactory, such systems could be connected to electric grid. In our research laboratory we must build an experimental setup. The simulation for wind turbine and fixed displacement pump coupled to it will be realized using a variable displacement piston pump. As the variable wind speed has as a result variations of the pump flow, the variable displacement pump from the test rig may reproduce a similar variation law. In this paper some aspects regarding the variable displacement pump are detailed. This study is necessary for the future development of the research.
\end{abstract}

\section{Introduction}

Although the technology in wind turbines has developed rapidly there are still a lot that can be improved and new technologies emerge frequently. One example is wind turbine with hydraulic transmission. The long term goal is to see if a mid-size wind turbine with a hydraulic transmission is suitable for the commercial market.

In recent years mathematical models of fluid power transmission systems in wind turbines were developed and validated at the TU Delft. Laboratory experiments were successfully carried out at scales of $600 \mathrm{~W}$ (validation of control method with water hydraulics \& rotor in wind tunnel) and 10kW (coupled oil and water circuits). Another set of experiments was carried out using the 1MW test rig (oil) at the Institute for Fluid Power Drives and Controls (IFAS) at RWTH Aachen University [1, 2].

Considering the case of low power wind turbines, the structure of such a system is presented in Figure 1. As one can see there is a positive displacement pump coupled directly to the turbine. For the protection there is a brake. The pump is coupled hydraulic at hydraulic motor through the high pressure line and the low pressure line. At the hydraulic motor axle may be coupled in order that isolated users to extract wind energy and use it for household and garden equipment or pumping water.

\footnotetext{
*Corresponding author: iddtita@yahoo.com
} 
It is important that if possible to configure the fluid power transmission system in such a way that no form of active control is required for the hydraulic transmission. In these conditions passive control is an inherent characteristic of the system.

Considering the future development of wind turbines with hydraulic transmissions one must try to answer some justified questions:

- Will a hydrostatic transmission be able to control the speed of the generator, so that the generated electricity satisfies the electric grid standards during normal operational conditions, without the use of a power converter?

- Can the drivetrain be realized by using already existing standard components?

- Can the system have a good overall efficiency?

- Is it possible to place some of the powertrain components in the nacelle and some of the components close to the ground to reduce weight in the nacelle and enable easier maintenance of some components? [3].

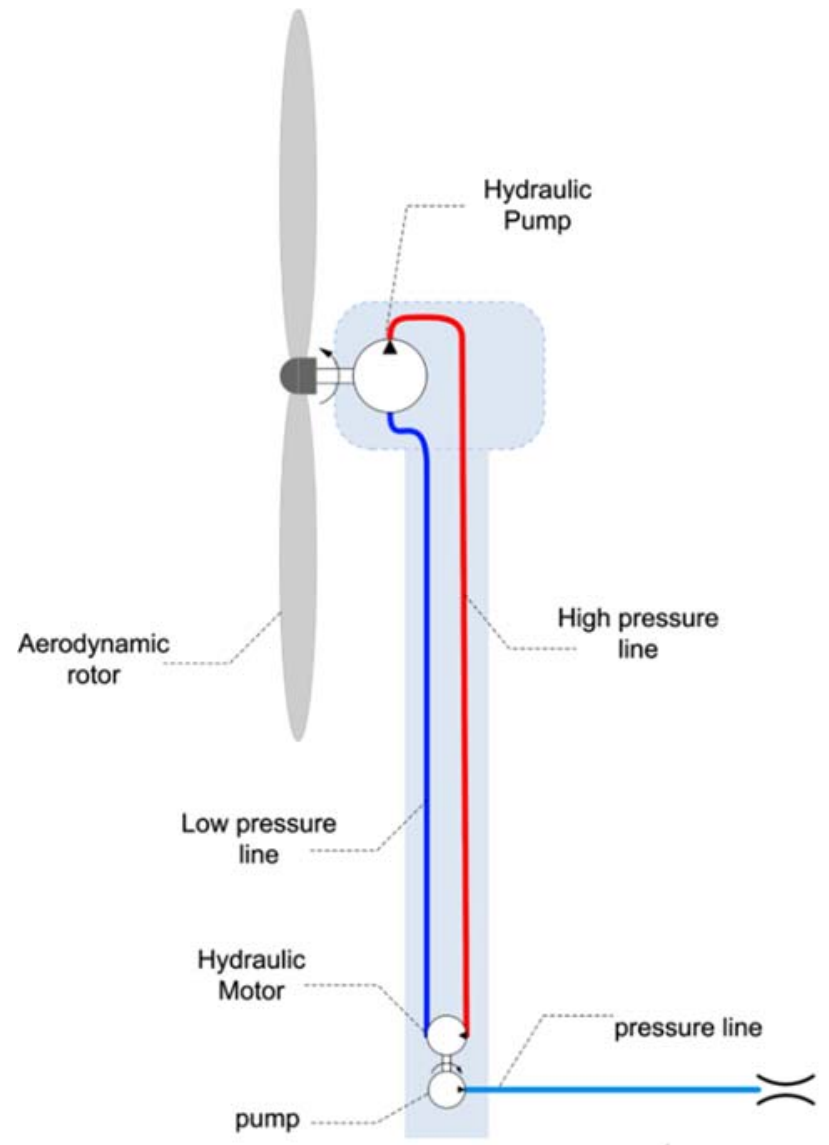

Fig. 1. Structure of wind turbine with hydraulic system [1].

In order to study such a system it must be configured an experimental rig. The simulation for wind turbine and fixed displacement pump coupled to it will be realized using a variable displacement piston pump. As the variable wind speed has as a result variations of the pump flow, the variable displacement pump from the test rig may reproduce a similar variation law [4]. 


\section{Primary control in hydraulic systems}

The hydraulic system consists of a hydrostatic transmission built of a variable-displacement pump, a fixed - displacement motor, and fixed displacement pump as a booster pump, pressure relief valves and check valves $[5,6]$. The schematic of closed circuit hydrostatic transmission system is presented in Figure 2.

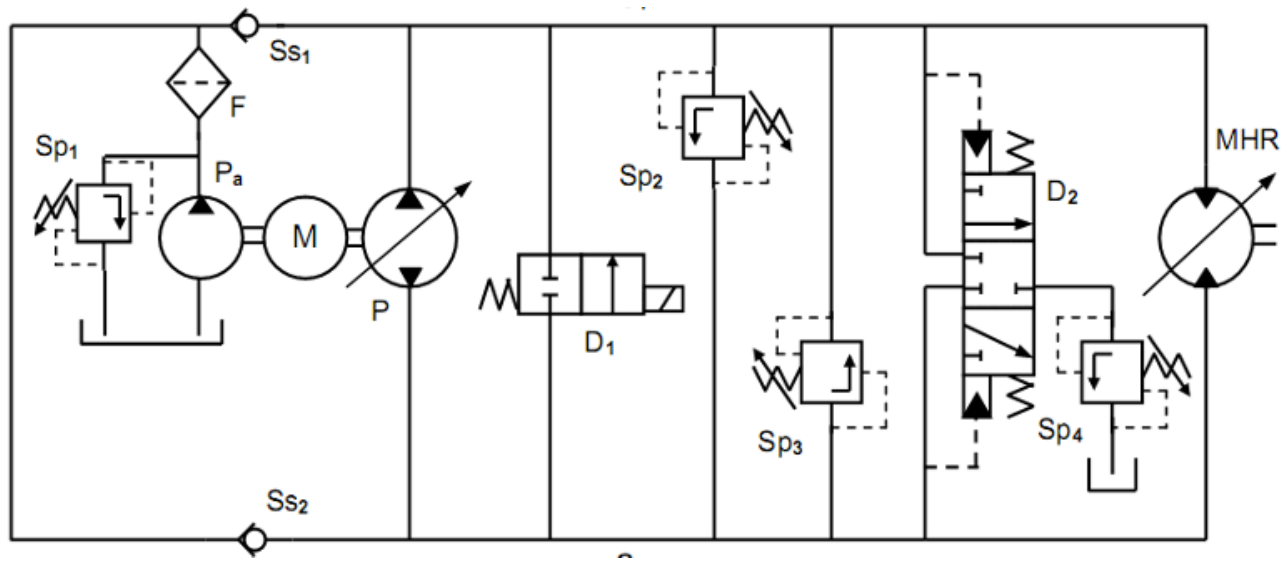

Fig. 2. Hydraulic system with variable displacement pump.

Equations for the system are as follows [7 - 9].

The pump outlet flow:

$$
Q_{1 p}=V_{p} \cdot \omega_{p}-\frac{p_{1}}{R_{p}}+\frac{p_{2}}{R_{i}}
$$

where: $\mathrm{V}_{\mathrm{p}}$ is displacement of hydraulic pump $\left[\mathrm{m}^{3} \cdot \operatorname{rot}^{-1}\right], \omega_{\mathrm{p}}$ is rotational speed at pump axle $\left[\mathrm{rad} \cdot \mathrm{s}^{-1}\right], \mathrm{p}_{1}$ is pressure at pump outlet $\left[\mathrm{N} \cdot \mathrm{m}^{-2}\right], \mathrm{p}_{2}$ is pressure at pump inlet $\left[\mathrm{N} \cdot \mathrm{m}^{-2}\right], \mathrm{R}_{\mathrm{p}}$ is output resistance for the pump $\left[\mathrm{N} \cdot \mathrm{m}^{-2} / \mathrm{m}^{3} \cdot \mathrm{s}^{-1}\right], \mathrm{R}_{\mathrm{i}}$ is internal resistance $\left[\mathrm{N} \cdot \mathrm{m}^{-2} / \mathrm{m}^{3} \cdot \mathrm{s}^{-1}\right]$.

The motor inlet flow:

$$
Q_{1 m}=V_{m} \cdot \omega_{m}+\frac{p_{1}}{R_{m}}-\frac{p_{2}}{R_{i}}
$$

where: $\mathrm{V}_{\mathrm{m}}$ is displacement of hydraulic motor $\left[\mathrm{m}^{3} \cdot \operatorname{rot}^{-1}\right], \omega_{\mathrm{m}}$ is rotational speed at motor axle $\left[\mathrm{rad} \cdot \mathrm{s}^{-1}\right], \mathrm{p}_{1}$ is pressure at motor outlet $\left[\mathrm{N} \cdot \mathrm{m}^{-2}\right], \mathrm{p}_{2}$ is pressure at motor inlet $\left[\mathrm{N} \cdot \mathrm{m}^{-2}\right], \mathrm{R}_{\mathrm{m}}$ is output resistance for the motor $\left[\mathrm{N} \cdot \mathrm{m}^{-2} / \mathrm{m}^{3} \cdot \mathrm{s}^{-1}\right], \mathrm{R}_{\mathrm{i}}$ is internal resistance $\left[\mathrm{N} \cdot \mathrm{m}^{-2} / \mathrm{m}^{3} \cdot \mathrm{s}^{-1}\right]$.

The motor outlet flow:

$$
Q_{2 m}=V_{m} \cdot \omega_{m}+\frac{p_{1}}{R_{i}}-\frac{p_{2}}{R_{m}}
$$

The pump inlet flow:

$$
Q_{2 p}=V_{p} \cdot \omega_{p}-\frac{p_{1}}{R_{i}}+\frac{p_{2}}{R_{p}}
$$


Considering:

$$
\begin{gathered}
\frac{1}{R_{p}}=\left(\frac{1}{R_{e}}+\frac{1}{R_{i}}\right)_{p} \text { and } \frac{1}{R_{m}}=\left(\frac{1}{R_{e}}+\frac{1}{R_{i}}\right)_{m} \\
\frac{1}{R_{e p}}=\left(\frac{V_{p} \cdot \omega_{p}}{E}+\frac{1}{R_{e x t}}+\frac{1}{R_{t i m}}\right)_{p} \text { and } \frac{1}{R_{e m}}=\left(\frac{V_{m} \cdot \omega_{m}}{E}+\frac{1}{R_{e x t}}+\frac{1}{R_{t i m}}\right)_{m}
\end{gathered}
$$

where: $R_{p}$ is output resistance for the pump $\left[\mathrm{N} \cdot \mathrm{m}^{-2} / \mathrm{m}^{3} \cdot \mathrm{s}^{-1}\right], \mathrm{R}_{\mathrm{m}}$ is output resistance for the motor $\left[\mathrm{N} \cdot \mathrm{m}^{-2} / \mathrm{m}^{3} \cdot \mathrm{s}^{-1}\right], \mathrm{R}_{\mathrm{i}}$ is internal resistance $\left[\mathrm{N} \cdot \mathrm{m}^{-2} / \mathrm{m}^{3} \cdot \mathrm{s}^{-1}\right], \mathrm{R}_{\mathrm{e}}$ is external resistance $\left[\mathrm{N} \cdot \mathrm{m}^{-2} / \mathrm{m}^{3} \cdot \mathrm{s}^{-1}\right], R_{\mathrm{ep}}$ is external resistance for the pump $\left[\mathrm{N} \cdot \mathrm{m}^{-2} / \mathrm{m}^{3} \cdot \mathrm{s}^{-1}\right], \mathrm{R}_{\mathrm{em}}$ is external resistance for the motor $\left[\mathrm{N} \cdot \mathrm{m}^{-2} / \mathrm{m}^{3} \cdot \mathrm{s}^{-1}\right], \mathrm{R}_{\text {ext }}$ is external leakage resistance $\left[\mathrm{N} \cdot \mathrm{m}^{-2} / \mathrm{m}^{3} \cdot \mathrm{s}^{-1}\right]$, $\mathrm{R}_{\text {tim }}$ is timing groove resistance $\left[\mathrm{N} \cdot \mathrm{m}^{-2} / \mathrm{m}^{3} \cdot \mathrm{s}^{-1}\right], \mathrm{E}$ is bulk modulus of hydraulic oil $\left[\mathrm{N} \cdot \mathrm{m}^{-2}\right]$.

From the equations of the pump outlet flow rate and the motor inlet flow rate:

$$
\begin{aligned}
& V_{p} \cdot \omega_{p}-\frac{p_{1}}{R_{p}}+\frac{p_{2}}{R_{i}}=V_{m} \cdot \omega_{m}+\frac{p_{1}}{R_{m}}-\frac{p_{2}}{R_{i}} \\
& V_{m} \cdot \omega_{m}=V_{p} \cdot \omega_{p}-p_{1} \cdot\left(\frac{1}{R_{p}}+\frac{1}{R_{m}}\right)+\frac{2 p_{2}}{R_{i}}
\end{aligned}
$$

The torque equations for the pump and the motor:

$$
\begin{aligned}
& M_{p}=V_{p} \cdot\left(p_{1}-p_{2}\right)+c_{v} \cdot \omega_{p}+M_{s c p} \\
& M_{m}=V_{m} \cdot\left(p_{1}-p_{2}\right)-c_{v} \cdot \omega_{m}-M_{s c m}
\end{aligned}
$$

where: $\mathrm{M}_{\mathrm{p}}$ is torque at pump axle $[\mathrm{N} \cdot \mathrm{m}], \mathrm{M}_{\mathrm{m}}$ is torque at motor axle $[\mathrm{N} \cdot \mathrm{m}], c_{v}$ is viscous friction coefficient $\left[\mathrm{N} \cdot \mathrm{m} / \mathrm{rad} \cdot \mathrm{s}^{-1}\right], \mathrm{M}_{\mathrm{scp}}$ is torque embracing striction and coulomb friction at pump axle $[\mathrm{N} \cdot \mathrm{m}], \mathrm{M}_{\mathrm{scm}}$ is torque embracing striction and coulomb friction at pump axle $[\mathrm{N} \cdot \mathrm{m}]$.

The transmission may be evaluated with:

$$
\begin{gathered}
\frac{1}{R_{1}}=\left(\frac{1}{R_{p}}+\frac{1}{R_{m}}-\frac{2}{R_{i}}\right) \text { and } \frac{1}{R_{2}}=\left(\frac{1}{R_{p}}+\frac{1}{R_{m}}\right) \\
\frac{\omega_{p}}{\omega_{m}}=\frac{\frac{V_{p}}{V_{m}}-\frac{M_{m}}{\omega_{p} \cdot R_{2} \cdot V_{m}^{2}}-\left[\frac{p_{2}}{\omega_{p} \cdot R_{1} \cdot V_{m}}+\frac{M_{s c m}}{\omega_{p} \cdot R_{2} \cdot V_{m}^{2}}\right]}{\left[1+\frac{c_{v}}{V_{m}^{2} \cdot R_{2}}\right]} \\
p_{1}=p_{2}+\frac{M_{m}}{V_{m}}+\frac{c_{v} \cdot \omega_{p}}{V_{m}} \cdot \frac{\omega_{m}}{\omega_{p}}+\frac{M_{s c m}}{V_{m}}
\end{gathered}
$$




$$
\frac{M_{m}}{M_{p}}=\frac{\left(p_{1}-p_{2}\right)-\frac{c_{v} \cdot \omega_{p}}{V_{m}} \cdot\left(\frac{\omega_{m}}{\omega_{p}}\right)-\frac{M_{s c m}}{V_{m}}}{\left(p_{1}-p_{2}\right) \cdot\left(\frac{V_{p}}{V_{m}}\right)+\frac{c_{v} \cdot \omega_{p}}{V_{m}}+\frac{M_{s c p}}{V_{m}}}
$$

The transmission efficiency is:

$$
\eta_{\text {tran }}=\frac{M_{m} \cdot \omega_{m}}{M_{p} \cdot \omega_{p}}
$$

In the laboratory of Wind Turbine Control Systems, from the Department of Fluid Mechanics, Fluid Machinery and Fluid Power Systems it is used a variable displacement axial piston pump PV023L1K1T1NUPK with maximum displacement $\mathrm{V}_{\mathrm{p}}=23 \mathrm{~cm}^{3} / \mathrm{rot}=$ $3,66 \cdot 10^{-6} \mathrm{~m}^{3} / \mathrm{rad}$, nominal pressure of $350 \cdot 10^{5} \mathrm{~N} / \mathrm{m}^{2}$, maximum pressure of $420 \cdot 10^{5} \mathrm{~N} / \mathrm{m}^{2}$, speed between 400 and $3000 \mathrm{rot} / \mathrm{min}$, moment of inertia $0,0017 \mathrm{~kg} \cdot \mathrm{m}^{2}$. Positive displacement motor has $\mathrm{V}_{\mathrm{m}}=4 \cdot 10^{-6} \mathrm{~m}^{3} / \mathrm{rad}$, the rotational speed of the pump is $\omega_{\mathrm{p}}=1440 \mathrm{rpm}$, external and internal resistances are $R_{\mathrm{e}}=0,5 \cdot 10^{12} \mathrm{~N} \cdot \mathrm{m}^{-2} / \mathrm{m}^{3} \mathrm{~s}^{-1}$ and $\mathrm{R}_{\mathrm{i}}=$ $2 \cdot 10^{12} \mathrm{~N} \cdot \mathrm{m}^{-2} / \mathrm{m}^{3} \cdot \mathrm{s}^{-1}$. Viscous friction coefficient is $\mathrm{c}_{v}=0,02 \mathrm{~N} \cdot \mathrm{m} / \mathrm{rad} \cdot \mathrm{s}^{-1}$.

Using same kind of hydraulic machine torque embracing striction and coulomb friction at pump axle is considered to be equal with torque embracing striction and coulomb friction at motor axle $\mathrm{M}_{\mathrm{scp}}=\mathrm{M}_{\mathrm{scm}}=6 \mathrm{~N} \cdot \mathrm{m}$. The pressure from the auxiliary pump set at pressure valve $\mathrm{Sp}_{1}$ is $6 \cdot 10^{5} \mathrm{~N} / \mathrm{m}^{2}$.

On the basis of equation (5) $R_{p}=R_{m}=0,48 \cdot 10^{12} \mathrm{~N} \cdot \mathrm{m}^{-2} / \mathrm{m}^{3} \mathrm{~s}^{-1}$ and equation (11), there result $\mathrm{R}_{1}=0,35 \cdot 10^{12} \mathrm{~N} \cdot \mathrm{m}^{-2} / \mathrm{m}^{3} \mathrm{~s}^{-1}$ and $\mathrm{R}_{2}=0,24 \cdot 10^{12} \mathrm{~N} \cdot \mathrm{m}^{-2} / \mathrm{m}^{3} \mathrm{~s}^{-1}$.

On the above considerations equation (12) is

$$
\frac{\omega_{p}}{\omega_{m}}=\frac{\frac{V_{p}}{V_{m}}-\frac{M_{m}}{578,8}-0,0132}{1,0052}
$$

Equation (13) gives pressure $\mathrm{p}_{1}\left[\mathrm{~N} / \mathrm{m}^{2}\right]$ :

$$
p_{1}=6 \cdot 10^{5}+2,56 \cdot 10^{5} \cdot M_{m}+7,54 \cdot 10^{5} \cdot \frac{\omega_{m}}{\omega_{p}}+15 \cdot 10^{5}
$$

Equation (14)

$$
\frac{M_{m}}{M_{p}}=\frac{\left(p_{1}-6\right) \cdot 10^{5}-7,54 \cdot 10^{5} \cdot\left(\frac{\omega_{m}}{\omega_{p}}\right)-15 \cdot 10^{5}}{\left(p_{1}-6\right) \cdot 10^{5} \cdot\left(\frac{V_{p}}{V_{m}}\right)+7,54 \cdot 10^{5}+15 \cdot 10^{5}}
$$

From (16), for $\mathrm{V}_{\mathrm{p}} / \mathrm{V}_{\mathrm{m}}=0,915$ we obtained graphic variation in Figure 3 for speed ratio, and from (17) considering $\mathrm{p}_{1 \max }=300 \cdot 10^{5} \mathrm{~N} / \mathrm{m}^{2}$ graphic variation for $\mathrm{p}_{1} / \mathrm{p}_{1 \max }$. 

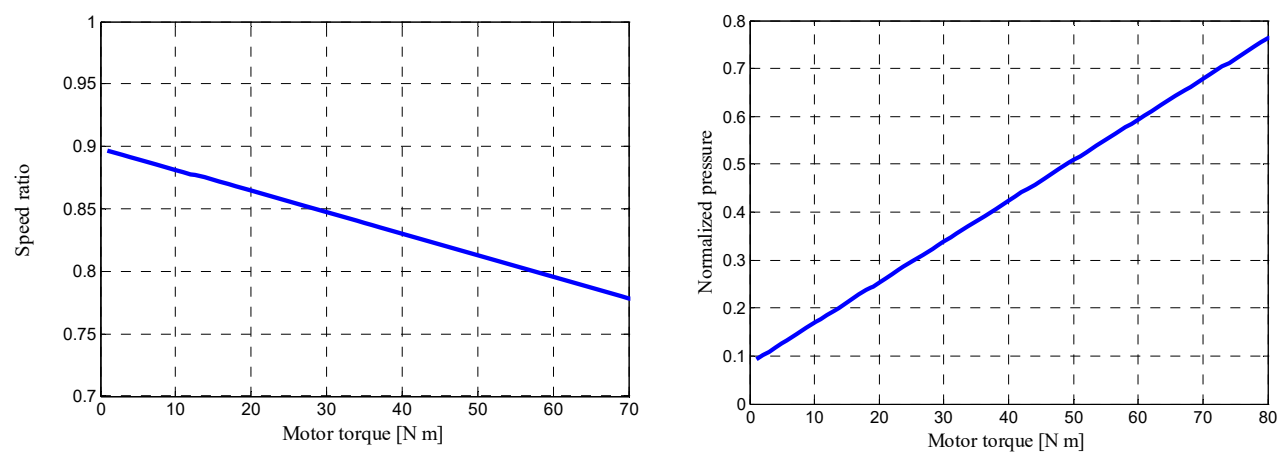

Fig. 3. Normalized variation speed.

\section{Conclusions}

Although the technology in wind turbines has developed rapidly there are still a lot that can be improved and new technologies emerge frequently. One example is wind turbine with hydraulic transmission.

In order to study the behavior of hydrostatic transmission it is important to design a test rig including the hydrostatic transmission and the components used to simulate wind turbine and fixed displacement pump coupled to it which will be realized using a variable displacement piston pump .

Considering the final purpose of the research which consists in hydrostatic transmissions for wind turbines, the main specific problems the way to configure the wind turbine and the connected pump was identified.

The authors would like to acknowledge the technical resources offered by the Laboratory of Wind Turbine Control Systems, from the Department of Fluid Mechanics, Fluid Machinery and Fluid Power Systems, "Gheorghe Asachi" Technical University of Iasi, Romania. The Laboratory of Wind Turbine Control Systems has been equipped with technical resources with the financial support of the grant ENERED, POSCCE-A2-O2.2.1-2009-4, ID 911.

\section{References}

1. N. Diepeveen, A.J. Laguna, 9IFK, 3, 12, (2014)

2. J. Schmitz, G. Matthiesen, H. Murrenhoff, , 9IFK, 3, 9, (2014)

3. Z. Jiang, L. Yang, Z. Gao, T. Moan, Energy Procedia, 53, 12 (2014).

4. A. Nikranjbar, A.N. Sharbabaki, Majlesi Journal of Energy Management, 2, 6, (2013).

5. K.E. Rydberg, The 11-th Scandinavian International Conference on Fluid Power, SICFP'09, June 2-4, Linköping, Sweden, (2009).

6. H. Murenhoff, Proceeding of the 12th International Conference on Tools: ICT-2007: September 6-8, Miskolc, (2007).

7. J. Watton, Fundamentals of Fluid Power Control (Cambridge University Press, London, 2009).

8. J. Watton, Modelling, Monitoring and Diagnostic Techniques for Fluid Power Systems, (Springer Verlag, London, 2007).

9. D. Zahariea, Applied Mechanics and Materials, 656, 5, (2014) 